\title{
Manufacturing of Long Products Made of Innovative Lightweight Materials
}

\author{
Karsten Richter $^{1} \cdot$ Roland Müller $^{1} \cdot$ Andreas Kunke $^{2} \cdot$ Verena Kräusel $^{2} \cdot$ Dirk Landgrebe $^{1,2}$
}

Received: 6 July 2015/Revised: 15 October 2015/Published online: 8 December 2015

(C) The Chinese Society for Metals and Springer-Verlag Berlin Heidelberg 2015

\begin{abstract}
The processing of innovative lightweight materials to sheet metal components and assemblies with globally or locally defined properties is the object of this work. It takes a load-dependent design of components and assemblies, for example, based on the composition of different construction materials or a targeted setting of component areas with specified characteristics to fully exploit the lightweight potential when substituting conventionally used materials. Different process chains for the manufacturing of roll-formed long products made of magnesium alloys and high-strength steels with locally defined properties will be presented in this paper. Depending on the kind of material to be formed and the desired product characteristics, different temperature managements are needed for capable processes. Due to limited formability at room temperature, magnesium alloys require a heating of the forming zones above $200-225^{\circ} \mathrm{C}$ throughout the bending process in order to activate additional gliding planes and to avoid any failures in the radii. The realization of local hardening effects requires at least one process-integrated heat treatment when roll forming manganese-boron steels. For both processes, it is imperative to realize a heating and cooling down or quenching appropriate for the manufacturing of long products with the required quality. Additionally, proper line speeds that allow a continuously operated economical production have to be considered. Research results including design, FEA, realization and experimentation of the mentioned process chains and strategies will be described in detail.
\end{abstract}

KEY WORDS: Roll forming; Heat treatment; Lightweight component; Light metals; Manganese steels; AZ31 magnesium alloy

Available online at http://link.springer.com/journal/40195

Karsten Richter

karsten.richter@iwu.fraunhofer.de

1 Fraunhofer Institute for Machine Tools and Forming Technology (IWU), Reichenhainer Str. 88, 09126 Chemnitz, Germany

2 Professorship Forming and Joining (UFF), Technische Universität Chemnitz, Reichenhainer Str. 70, 09126 Chemnitz, Germany

\section{Introduction}

\subsection{Lightweight Design Using Profiles}

Lightweight design is an overall trend that is driven by automotive manufacturing but has spread to other industries as well. Background is the scarcity of natural resources and energy that has led to an increasing awareness for the necessity of a resource and energy efficiency during the entire life cycle of products. The automotive industry has thus focused increasingly on the reduction of vehicle weights. Due to rising requirements for safety and comfort, the aimed goals are hardly attainable. Nevertheless, major efforts are required to fulfil customer demands of low fuel consumption and legal standards. According to 
these governmental regulations, the average $\mathrm{CO}_{2}$ emission of the car manufacturer's fleet in Europe needs to be reduced to an average of $120 \mathrm{~g} / \mathrm{km}$ by 2015 and $95 \mathrm{~g} / \mathrm{km}$ by 2020 [1]. In the case of excessive increase, high penalties can be imposed: exceedance of $\mathrm{CO}_{2}$-emission limits by $1 \mathrm{~g} / \mathrm{km}$ will be punished with $5 € / \mathrm{g}$ per vehicle, and excessive increase in more than $3 \mathrm{~g} / \mathrm{km}$ costs $95 € / \mathrm{g}$ [1].

The disregard of legal regulations could mean significant financial losses for car manufacturers. Thus, ongoing innovations in research and development in the automotive industry are imperative.

In order to achieve weight reduction, different approaches are currently being pursued: material lightweight design, structural lightweight design, conditional lightweight design, manufacturing methods for lightweight design and conceptual lightweight design [2].

Numerous studies on body concepts for the automotive and commercial vehicle industry have been conducted, dealing with different strategies in lightweight design. An example for innovative concepts in cabin design has been developed within the InTruck project [3]. A considerable number of linear and bent profiles represent the product group of long products being explored for the cabin of a commercial vehicle.

Within the Atlas project of Salzgitter AG and Wilhelm Karmann $\mathrm{GmbH}$, steel car bodies were developed using the innovative space frame technology for the first time. Structural framework parts are made of closed steel profiles which were produced by hydroforming or roll forming. The application of high-strength steels and adapted manufacturing methods offers the opportunity to implement solid and stiff structures with a reduced sheet metal thickness. Furthermore, weight reductions of about $20 \%$, cost reductions for single components up to $20 \%$ and less tool costs up to $30 \%$ are possible [4].

\subsection{Semi-finished Products for Components with Graded Properties}

As was indicated in numerous examples and studies, the fabrication of sustainable and economical products significantly depends on the consideration and application of innovative lightweight technologies. The aim is to implement the appropriate material and design at the corresponding place. The B-pillar of new cars offers an ideal example for continuous improvements and the suitable use of lightweight construction strategies. In the case of side impacts, the function of that component is to absorb the impact energy while protecting the passenger compartment. Locally distinguished component properties are necessary to assure an optimal crash resistance. For the selected concepts for B-pillars within the InCar project, the applied structural parts consist either of tailored welded blanks (same or different material with different sheet thicknesses) or they are fabricated by tailored tempering [5].

Tailored tempering belongs to advanced developments of press hardening (hot stamping). The fabrication route consists of hot sheet metal forming with a subsequent quenching process. Components with a tensile strength of up to $1900 \mathrm{MPa}$ can be manufactured using tailored tempering. Locally diverging component properties at distinctive spots within components can be set by a targetorientated variation of heating temperatures and cooling rates.

Further fabrication approaches to design components with tailored properties are forming of tailor rolled blanks (components changing sheet thickness within one piece) and forming of locally reinforced sheets (Patchwork Technology).

\subsection{Tempered Roll Forming: State of the Art}

\subsubsection{Roll Forming in General}

Roll forming is a highly productive forming technology which is based on bending with a rotary tool motion. The most common approach is to form profiles with a uniform cross section. George Halmos has defined the technology as follows: 'to form sheet metal strip along straight, longitudinal, parallel bend lines with multiple pairs of contoured rolls without changing the thickness of the material at room temperature' [6]. The standard set-up is to use an uncoiler, a straightener and a roll forming machine that can consist of up to a high double digit number of consecutive roll forming stands mainly depending on the geometrical complexity of the profile and the forming behaviour of the used material. The main advantages of the technology are the wide spectrum of profile geometries possible, the achievable dimensional accuracy, the systematic utilization of cold work hardening phenomena and the energy efficiency [7] coming along with the large possible output. Standard materials in industrial use are steel and aluminium grades that are formed in profiles with user-defined variable length at room temperature. The technology is particularly advantageous when producing a large number of same parts. Furthermore, other processes like punching, notching, mechanical or thermal cutting and laser welding can be integrated quite easily in roll forming lines.

\subsubsection{Roll Forming with Integrated Heat Treatment}

Currently roll forming with an integrated heat treatment has not been industrially applied. There are, however, many patent ideas describing the basic principle of the 
method and relevant component applications. The induction heating is the preferred method for this continuous process, while air, water or other cooling media are suitable techniques for quenching [8]. Furthermore, detailed process variants (temperature gradients, component areas of heat treatment, cooling step by step, etc.) for the manufacturing of various car body components with defined properties are shown in a patent proposal of Linde + Wiemann GmbH [9].

\subsubsection{Temperature-Assisted Roll Forming}

Dating back as far as 1971, studies have been conducted on heat assistance in roll forming processes. As roll forming at room temperature had not generated favourable results, radiant lamps were used by Boeing to heat titanium strips to $800{ }^{\circ} \mathrm{C}$ in order to enhance formability. Main advantages of a roll forming with heat assistance detected by Foster [10] were the reductions of the achievable radii in the profiles, the roll forming stands necessary during the execution of the forming process, the drive power necessary and both shaft and roll diameters allowing cheaper tooling.

Another approach pursued is integrating laser technology into roll forming lines. As of today, lasers are often used for profile welding, for example, when producing tubes or other closed profiles. In spite of strong academic efforts at the Universities of Erlangen and Vienna as well as at the research centre AIMEN to use diode lasers to locally improve forming behaviour in roll forming processes, no industrial applications have emerged. Both at the Erlangen University and the Vienna University, simple test facilities were assembled in which the active principles of the process were inverted. While the sheet remains stationary, a roll combined with a laser head was moved along the sheet strips. Experiments at Erlangen University proved that for a MSW1200 with a thickness of $t=1.6 \mathrm{~mm}$, bending angles $\alpha$ could be improved by more than $80^{\circ}$ at $690{ }^{\circ} \mathrm{C}$ in which Pitz [11] accounted for the activation of additional slip systems and microstructural transformation. At Vienna University, a diode laser was implemented by Kratky [12] into the experimental set-up to form a 0.8-mmthick stainless sheet (X5CrNi1810, 1.4301) and a $0.5-\mathrm{mm}$ thick CK75 (1.1248) while varying parameters including the positioning of the roll forming stand, the penetration depth of upper rolls, the evolving contact pressure and the heating. Lindgren [13] used a resistance heating for partial heating experiments of TRIP steels at Dalarna University. An induction heating was suggested by Yan et al. [14] to investigate a warm roll forming of high-strength steels.

All the different laboratory-scale experiments demonstrated that higher incremental deformations can be attained in each forming stand when using local heating. It can be reasoned that fewer forming stages are required in heated roll forming compared to the reference at room temperature [15]. As any kind of heat integration into forming processes constitutes a cost issue, on the other hand a tendency can be observed to investigate formability in general and roll formability in particular even of materials that exhibit limited formability and high springback at room temperature. Recent experimental research and FEA studies on high-strength titanium alloys such as Ti-6Al-4V by Badr et al. [16] and magnesium wrought alloys by Juchmann et al. [17], Groche et al. [18], Kim et al. [19], Watari et al. [20] and Hanm and Lee [21] clearly show both the limitations of poor formability and the impact of springback on the shape accuracy. An exploitation of the benefits a roll forming at elevated temperatures has to offer thus seems promising.

\section{Experiments and Results}

\subsection{Roll Forming of Press Hardening Steels with Integrated Heat Treatment}

The combination of roll forming with heat treatment offers manufacturing routes for profiles with tailored properties in a continuous fabrication process. The favoured sheet metal material 22MnB5 reaches a tensile strength between $550 \mathrm{MPa}$ in delivery condition and $1500 \mathrm{MPa}$ after forming depending on the prior heat treatment. The technological process flow is comparable with the indirect press hardening process $[22,23]$. First the sheet is pre-formed in cold state, then locally heated up above austenitization temperature according to the component requirements and afterwards directly quenched while leaving the rollers. Figure 1 illustrates both the process and the demonstrator component schematically.

To determine the effects of heating and cooling rates, fundamental tests were carried out with the help of a circular inductor (diameter $D=50 \mathrm{~mm}$ ) and an induction heater. High heating rates lead to a significant increase in austenitisation temperature. On the basis of experimental investigations and FE simulations, two geometries for inductors were designed and manufactured for a continuous roll forming process, as shown in Fig. 2.

The empty space between two rollers in horizontal direction is considered for inductive heat treatment, which allows moderate heating rates. The inductor with retaining loops offers two different heating zones. In the first section, the sheet metal is rapidly heated up to Curie temperature $T_{\mathrm{C}}$. In the case of ferritic steels, the permeability changes above $770{ }^{\circ} \mathrm{C}$. Subsequently, the rise in temperature is lowered which results in a more homogeneous temperature distribution over the sheet thickness. To ensure a uniform and slow heating of the sheet, the holding effect is 
(a)

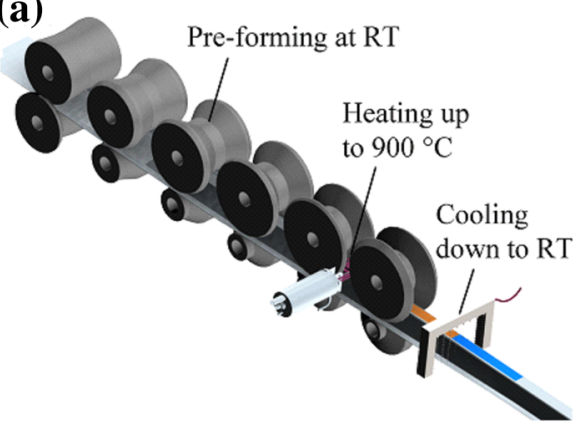

(b)

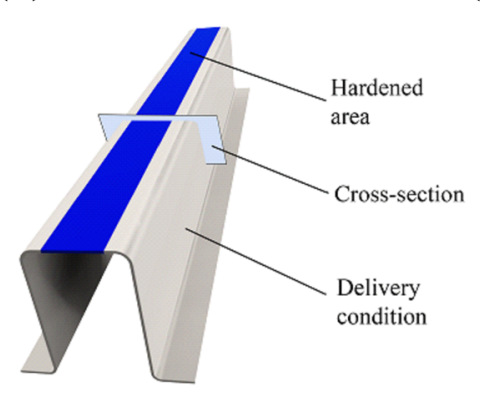

(c)

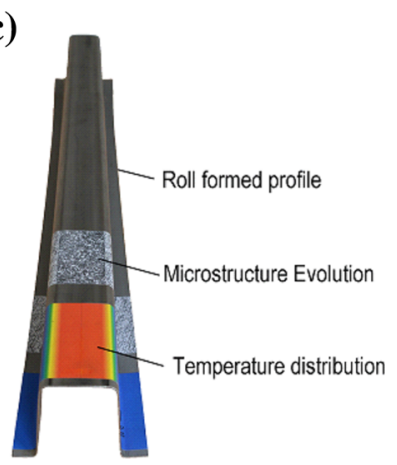

Fig. 1 Process a and demonstrator component $\mathbf{b}, \mathbf{c}$ of roll forming with integrated heat treatment

\section{Circular inductor}

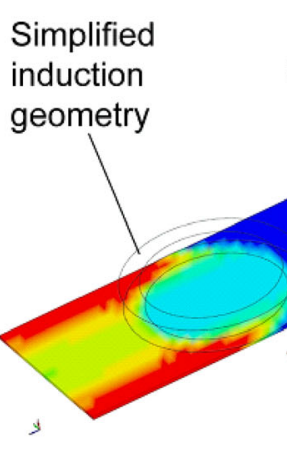

Inductor with loops in longitudinal (for heating) and transverse direction (for homogenization)
Meandering inductor

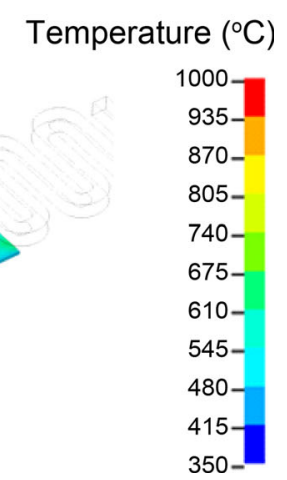

Fig. 2 Development of suitable inductor geometries using LS Dyna

increased by additional retaining loops. For experiments, a $50 \mathrm{~kW}$ SDF-ELDEC-frequency converter was applied. With a clearance between inductor and sheet of about $a=6 \mathrm{~mm}$, a maximum line speed of $v=1.2 \mathrm{~m} / \mathrm{min}$ could be achieved.

The emergence of the martensitic phase was proven both with microstructural characterizations and by hardness tests. For air-cooled specimens with a ferritic-perlitic structure, selective phase etching with nitric acid (3\% nital) was preferred. Rapidly cooled specimens with martensitic microstructure were etched with picric acid (4\% Picrate). Additionally, a determination of grain size (martensitic packet size) took place (see in Fig. 3).

The evaluation of different heat-treated samples results in a martensitic structure for heating with both inductors. The grain size is unequal due to different heating rates and temperatures. Differences in hardness occur for varying cooling mediums, where cooling by water spray results in hardness up to $530 \mathrm{HV}$. The feasibility and reproducibility of the technology have been tested on a top-hat profile, where one line is completely hardened in the longitudinal direction as shown in Fig. 4. The implementation of hardened zones transverse to the profile movement direction is only practical by appropriate heating strategies. The transition area between hardened and soft parts depends on the inductor length due to different dwelling times of the sheet underneath the inductor.

\subsection{Tempered Roll Forming of Magnesium Wrought Alloys}

Another approach to produce lightweight profiles utilizing elevated temperatures is the roll forming of magnesium wrought alloys. As generally known, the formability of magnesium is limited at room temperature due to its crystalline structure. Instead of five independent gliding planes necessary to ensure a plastic forming without damaging the basic material, the close-packed hexagonal structure of magnesium only features three independent gliding planes in basal level. Formability can be enhanced though by activating additional gliding planes by heating the material to temperatures higher than $200-225^{\circ} \mathrm{C}$. A temperature-supported forming of magnesium components already is available for a number of different forming technologies, e.g. deep drawing and hydroforming including the use of tailored blanks [24].

The roll forming of magnesium wrought alloys has not only been limited by the need for the integration of 

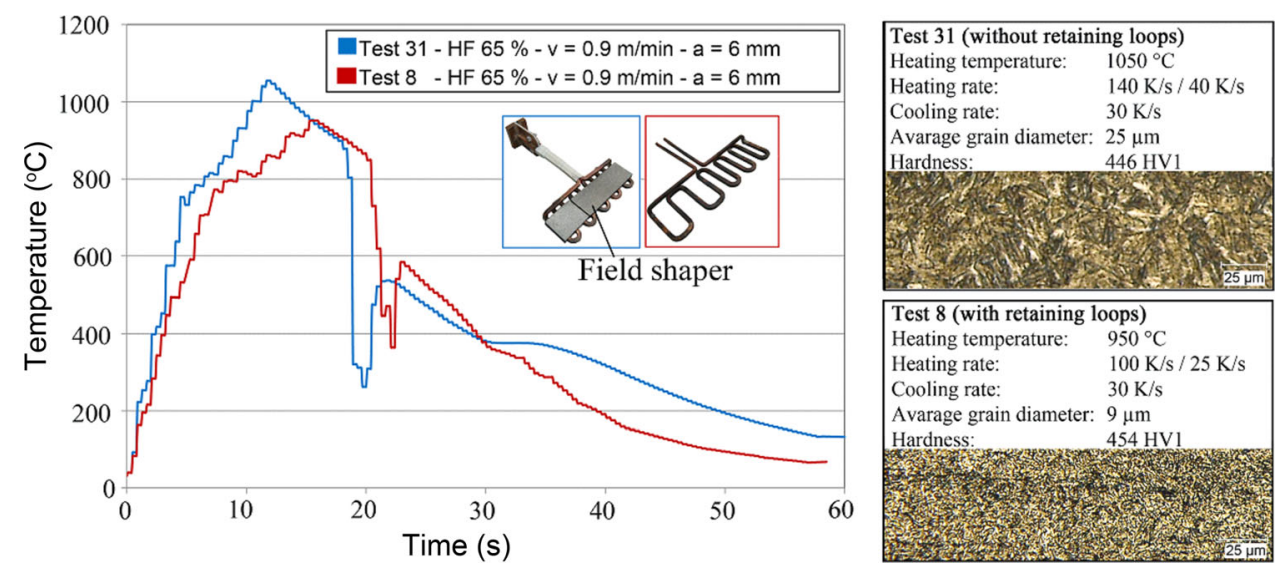

Fig. 3 Experimental results of heating for inductor with and without retaining loops
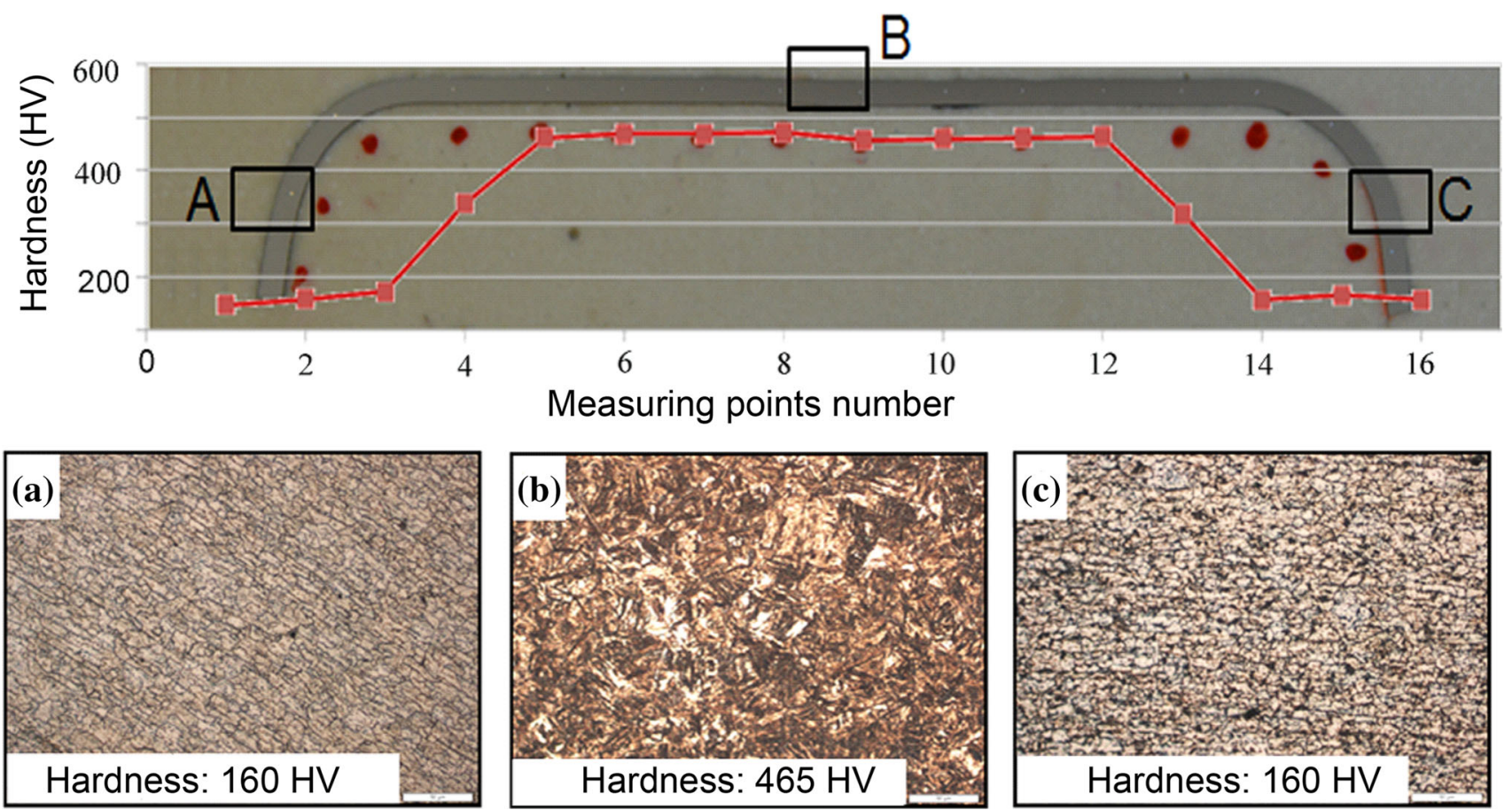

Fig. 4 Cross section of profile shown in Fig. 1 with graded properties (the spacing between two neighbouring hardness measuring points is $5.0 \mathrm{~mm})$

suitable heating concepts and devices but also by the specifics of the technology that is laid up for a rather big output of same parts, while the immediate availability of magnesium sheets and coils had not yet been pushed by an equivalent end-user demand. Experimentation to make long products of magnesium wrought alloys at elevated temperatures as described by Richter et al. [25] is a rather new application. Before that, focus was set on preliminary tests and FEA studies at room temperature [17-21].

The entire process chain was designed and set up for a profile as a component part of a lightweight rear backrest structure which was adapted from a real automotive structure. Substituting steel with the much lighter magnesium was made possible through the consistent use of open and closed profiles (Fig. 5) while revising the structure's concept with the help of a load-oriented crash simulation. Production technologies used for the different profiles include roll forming, three-point bending, extrusion moulding and hydroforming. The sheet metal thickness of the profile for roll forming was set at $3.0 \mathrm{~mm}$ using twin roll-casted AZ31-sheets [26] supplied by Magnesium Flachprodukte $\mathrm{GmbH}$ Freiberg. The profile contains different bending radii and angles $\left(R_{1}=5 \mathrm{~mm}, R_{2}=8 \mathrm{~mm}\right.$, $R_{3}=10 \mathrm{~mm}$ ). 


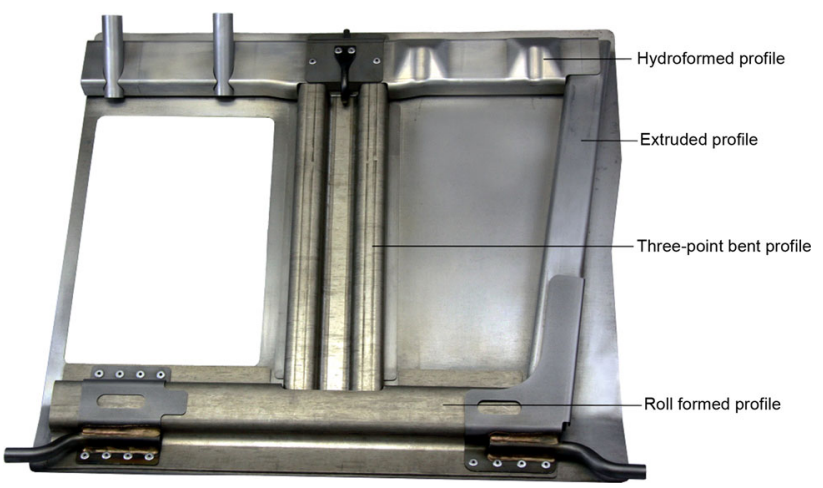

Fig. 5 Rear backrest structure composed of several profiles made of magnesium wrought alloys

The bending process (i.e. bending sequence, number and distance of roller stands, roll diameters and geometries) was designed and verified using isothermal flow curves at different temperature levels during FEA. The bending of the angles contained in the profile was distributed over five forming passes in increments of $\Delta \alpha=15^{\circ}-20^{\circ}$ per pass. As an example of the FEA results, the von Mises stress equivalent $\sigma_{\mathrm{v}}$ is shown in Fig. 6.

A transverse flux induction heating device provided by the project partner EMATEC and utilizing a frequency inverter with a nominal capacity of $P=50 \mathrm{~kW}$ was integrated into the roll forming machine. It works in a way that the continuously driven flat strip is moved through two inductors located on both the upper and lower side of the sheet metal. The heating occurs through the alternating magnetic field that is oriented perpendicularly to the strip surfaces and the resulting eddy current within the strip. Within the experimental set-up, five roller stands were needed. The inductive heating was put in place directly in front of the first stand to prevent too much energy loss to the surrounding air before the first contact with a forming tool. A secondary heating, in the form of an infrared postheating, was foreseen to influence the overall heat balance

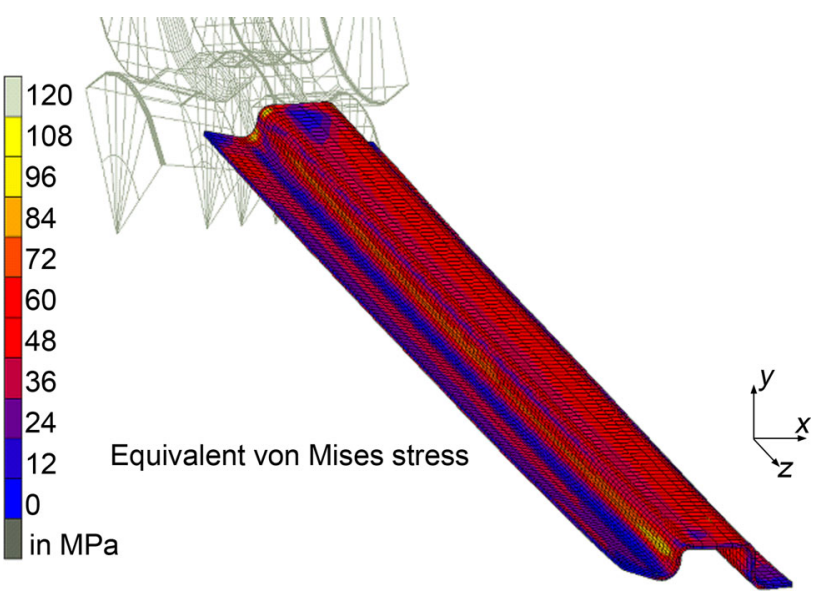

Fig. 6 FEA results of the magnesium profile (von Mises stress $\sigma_{\mathrm{v}}$ ) in case of critical thermal losses within the forming process in a positive way.

The optimization goals of achieving profiles without failures and a minimized ratio of bending radius to sheet thickness on the one hand and an economically reasonable line speed while still accomplishing a homogeneous heating on the other hand are contradictory. While homogeneous heating of the continuously driven strip demands a steady inductive heating and rather slow line speeds, the minimization of thermal losses due to the linear contact to the forming rolls and heat emission from sheet to air demands high line speeds. During the experimentation, it proved possible to reach a homogeneous heating of the sheets used with a thickness of $t=3.0 \mathrm{~mm}$ and a bandwidth of $b=152 \mathrm{~mm}$ while using the equipment described above. The maximum line speed attained was $v=3 \mathrm{~m} / \mathrm{min}$ while reaching an inlet temperature of $340{ }^{\circ} \mathrm{C}$ measured with a thermographic camera. The capacity of the frequency inverter, the distance between the sheet surface and the inductor, the length and geometry of the inductor and the line speed can be considered the main influencing factors of the heating results. While running the magnesium sheet strip through the feeding pass and the first two forming passes, the rather low line speed led to a thermal loss resulting in a temperature drop below the critical limit of $225^{\circ} \mathrm{C}$ with a temperature-dependent rate of $\Delta T=30-35{ }^{\circ} \mathrm{C}$ per forming pass. With the help of an infrared heating placed alternatively between the stands 2 and 3 or 3 and 4 , an elevation of the sheet temperature above $300{ }^{\circ} \mathrm{C}$ could be reached again. This enabled a forming of profiles without any macro-cracks but some beginning necking visible in the bending zone (Fig. 7).

A significant impact of metallographic and surface imperfections could be observed during the different trials. Already inconspicuous impurities or rolling marks did influence the forming result and generated a light graining not influencing the overall performance of the lightweight

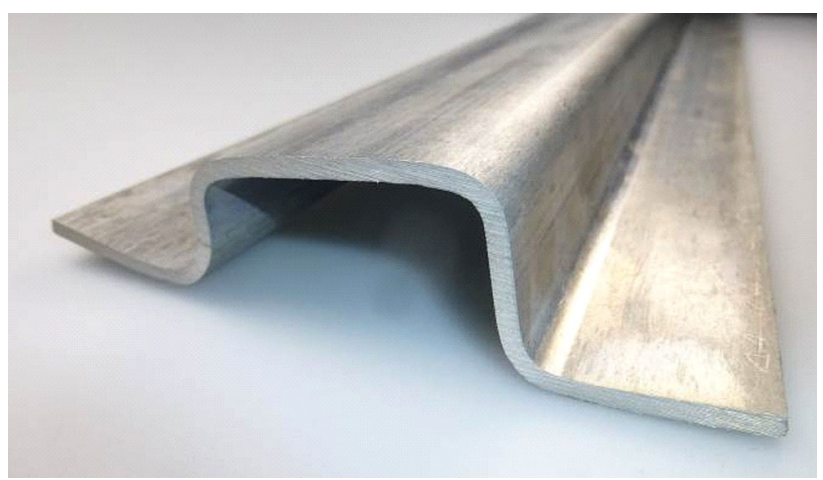

Fig. 7 Magnesium profile formed with a roll forming process containing both inductive and infrared heating 
profiles produced. The availability of a roll forming process to manufacture profiles out of magnesium sheets or coils opens new perspectives for this innovative material and for lightweight design taking advantage of the light yet stiff profiles.

\section{Conclusions}

A tempered roll forming process offers the opportunity to form long products of innovative lightweight materials with globally or locally defined properties. Research conducted with press hardening steels and magnesium wrought alloys shows the great potential the technology has to offer to future industrial lightweight applications. While the tempered roll forming of press hardening steels aims at setting the microstructure and the mechanical properties, a tempered roll forming of magnesium sheets aims at enabling the feasibility of light profiles made of this material at all.

Acknowledgments The topics and results presented in this paper are majorly based on two research and development projects 'TEMAKplus' and 'eniPROD' which have received funding by the Federal Government of Germany and the Free State of Saxony namely within the programs European Regional Development Fund and Innovative Regional Growth Cores.

\section{References}

[1] Verordnung (EG) Nr. 443/2009 des Europäischen Parlaments und des Rates Amtsblatt der Europäischen Union (CEP-Centrums für Europäische Politik, Brüssel, 2009), http://www.cep. eu/fileadmin/user_upload/cep.eu/cepMonitor/KOM_2007_856_ CO2-Ausstoss_neuer_Pkw/VO_EG_443_2009.pdf. Accessed 26 June 2015

[2] P. Kellner, Dissertation, Technische Universität Dresden (2014)

[3] InTruck-Innovation on road (ThyssenKrupp AG, 2013), www. thyssenkrupp.com. Accessed 26 June 2015

[4] Mit Stahl Gewicht einsparen, AutomobilKONSTRUKTION $(2009 / 001)$

[5] Das InCar-Projekt von ThyssenKrupp. ATZ extra, 56-71 (November 2009)
[6] G.T. Halmos, Roll Forming Handbook (CRC Taylor \& Francis, Boca Raton, 2006)

[7] J. Paralikas, K. Salonitis, G. Chryssolouris, Int. J. Adv. Manuf. Technol. 66, 1271 (2013)

[8] G. Lengauer, A. Schieder, A. Habacht, W. Buhl, F. Weitz, B. Lagler, A. Kreuzhuber, W. Brandstätter, DE 102007043154 A1, 02 April 2009

[9] E.G. Gücker, M. Ohlwein, M. Abel, DE 102007024797 A1, 27 Nov 2008

[10] G. Foster, Hot roll-forming shapes titanium for airframes, in High Production Roll Forming, ed. by G.T. Halmos (Society of Manufacturing Engineers, Dearborn, 1983), pp. 44-48

[11] M. Pitz, Laserunterstützes Biegen höchstfester Mehrphasenstähle (Meisenbach, Bamberg, 2005)

[12] A. Kratky, Laser assisted forming techniques, in Proceedings of the SPIE, ed. by D. Schuöcker, vol. 6346 (Wien, 2007)

[13] M. Lindgren, U. Bexell, L. Wikström, J. Mater. Proc. 209, 3117 (2009)

[14] H.J. Li, P.J. Yan, J.T. Han, Z.Y. Jiang, D.Y. Li, Adv. Mater. Res. 472-475, 2783 (2012)

[15] P.M. Romero, G. Rodíguez, J. Vázquez, Laser Assist. Net Shape Eng. 5, 597 (2007)

[16] O.M. Badr, B. Rolfe, P. Hodgson, M. Weiss, Mater. Des. 66, 618 (2015)

[17] P. Juchmann, S. Wolff, Mobile with magnesium sheet, in IMAProceedings 65th Annual World Magnesium Conference, Wauconda, 2008, pp. 75-84

[18] P. Groche, A.O. Zettler, R. Kawalla, Magnesium-Werkstoff für Profile der Zukunft?, in Proceedings of 3. Fachtagung Walzprofilieren, ed. by P. Groche (Meisenbach, Bamberg, 2002)

[19] D.H. Kim, D.H. Yoon, H. Yu, D.W. Jung, Adv. Mater. Res. 1016, 75 (2014)

[20] H. Watari, H. Hamano, S.I. Nishida, H. Aso, Appl. Mech. Mater. 459, 455 (2014)

[21] S.S. Hanm, M.Y. Lee, Mater. Res. Innov. 15, 270 (2011)

[22] P. Hippchen, A. Lipp, H. Grass, P. Craighero, M. Fleischer, M. Merklein, J. Mater. Proc. Technol. (2015). doi:10.1016/j. jmatprotec.2015.01.003

[23] R. Neugebauer, F. Schieck, S. Polster, A. Mosel, A. Rautenstrauch, J. Schönherr, N. Pierschel, Arch. Civ. Mech. Eng. 12, 113 (2012)

[24] F. Schieck, W.G. Drossel, H. Bräunlich, S. Scheffler, N. Pierschel, in ASME 2013 International Mechanical Engineering Congress and Exposition, IMECE 2013. doi:10.1115/ IMECE2013-63175

[25] K. Richter, R. Haase, F. Schieck, D. Landgrebe, Mater. Today Proc. 2, 60 (2015)

[26] K. Neh, M. Ullmann, M. Oswald, F. Berge, R. Kawalla, Mater. Today Proc. 2, 45 (2015) 